University of Wollongong

Research Online

Australian Institute for Innovative Materials -

Papers

Australian Institute for Innovative Materials

$1-1-2016$

\title{
Graphene-wrapped reversible reaction for advanced hydrogen storage
}

Guanglin Xia

Fudan University, University of Wollongong, gx168@uowmail.edu.au

Yingbin Tan

Fudan University

Feilong Wu

Fudan University

Fang Fang

Fudan University

Dalin Sun

Fudan University

See next page for additional authors

Follow this and additional works at: https://ro.uow.edu.au/aiimpapers

Part of the Engineering Commons, and the Physical Sciences and Mathematics Commons

Research Online is the open access institutional repository for the University of Wollongong. For further information contact the UOW Library: research-pubs@uow.edu.au 


\title{
Graphene-wrapped reversible reaction for advanced hydrogen storage
}

\author{
Abstract \\ Here, we report the fabrication of a graphene-wrapped nanostructured reactive hydride composite, i.e., \\ 2 LiBH4-MgH2, made by adopting graphene-supported $\mathrm{MgH} 2$ nanoparticles (NPs) as the nanoreactor and \\ heterogeneous nucleation sites. The porous structure, uniform distribution of $\mathrm{MgH} 2 \mathrm{NPs}$, and the steric \\ confinement by flexible graphene induced a homogeneous distribution of $2 \mathrm{LiBH} 4-\mathrm{MgH} 2$ nanocomposite \\ on graphene with extremely high loading capacity ( $80 \mathrm{wt} \%$ ) and energy density. The well-defined structural \\ features, including even distribution, uniform particle size, excellent thermal stability, and robust \\ architecture endow this composite with significant improvements in its hydrogen storage performance. \\ For instance, at a temperature as low as $350^{\circ} \mathrm{C}$, a reversible storage capacity of up to $8.9 \mathrm{wt} \% \mathrm{H} 2$, without \\ degradation after 25 complete cycles, was achieved for the $2 \mathrm{LiBH} 4-\mathrm{MgH} 2$ anchored on graphene. The \\ design of this three-dimensional architecture can offer a new concept for obtaining high performance \\ materials in the energy storage field.

\section{Keywords} \\ hydrogen, advanced, reaction, storage, reversible, graphene, wrapped \\ Disciplines \\ Engineering | Physical Sciences and Mathematics

\section{Publication Details} \\ Xia, G., Tan, Y., Wu, F., Fang, F., Sun, D., Guo, Z., Huang, Z. \& Yu, X. (2016). Graphene-wrapped reversible \\ reaction for advanced hydrogen storage. Nano Energy, 26 488-495.

\section{Authors} \\ Guanglin Xia, Yingbin Tan, Feilong Wu, Fang Fang, Dalin Sun, Zaiping Guo, Zhenguo Huang, and Xuebin Yu
}




\section{Graphene-wrapped Reversible Reaction for Advanced Hydrogen}

\section{Storage}

Guanglin Xia, ${ }^{a, b}$ Yingbin Tan, ${ }^{a}$ Feilong Wu,${ }^{a}$ Fang Fang, ${ }^{a}$ Dalin Sun, ${ }^{a}$ Zaiping Guo, ${ }^{* b}$ Zhenguo Huang, ${ }^{b}$ and Xuebin Yu*a

${ }^{a}$ Department of Materials Science, Fudan University, Shanghai, China.

${ }^{b}$ Institute for Superconducting and Electronic Materials, University of Wollongong, Wollongong, Australia.

${ }^{*}$ To whom correspondence should be addressed.

E-mail: yuxuebin@fudan.edu.cn; zguo@uow.edu.au 


\begin{abstract}
Here, we report the fabrication of a graphene-wrapped nanostructured reactive hydride composite, i.e., $2 \mathrm{LiBH}_{4}-\mathrm{MgH}_{2}$, made by adopting graphene-supported $\mathrm{MgH}_{2}$ nanoparticles (NPs) as the nanoreactor and heterogeneous nucleation sites. The porous structure, uniform distribution of $\mathrm{MgH}_{2} \mathrm{NPs}$, and the steric confinement by flexible graphene induced a homogeneous distribution of $2 \mathrm{LiBH}_{4}-\mathrm{MgH}_{2}$ nanocomposite on graphene with extremely high loading capacity (80 wt\%) and energy density. The well-defined structural features, including even distribution, uniform particle size, excellent thermal stability, and robust architecture endow this composite with significant improvements in its hydrogen storage performance. For instance, at a temperature as low as $350^{\circ} \mathrm{C}$, a reversible storage capacity of up to 8.9 wt.\% $\mathrm{H}_{2}$, without degradation after 25 complete cycles, was achieved for the $2 \mathrm{LiBH}_{4}-\mathrm{MgH}_{2}$ anchored on graphene. The design of this three-dimensional architecture can offer a new concept for obtaining high performance materials in the energy storage field.
\end{abstract}

Keywords: hydrogen storage, graphene, nanoparticles, borohydrides, magnesium hydrides. 


\section{Introduction}

Lithium borohydride $\left(\mathrm{LiBH}_{4}\right)$ has been widely investigated as one of the most promising solid-state materials for hydrogen storage due to its high gravimetric (18.5 wt.\%) and volumetric hydrogen density $\left(121 \mathrm{~kg} \mathrm{~m}^{-3}\right) .^{[1,2]}$ Its practical applications, however, are significantly restricted by the high thermodynamic stability and sluggish reaction kinetics of $\mathrm{LiBH}_{4}$, which are attributed to the strong ionic/covalent bonding between the constituent elements, which leads to a complete dehydrogenation only at temperatures exceeding $400{ }^{\circ} \mathrm{C}$ (Eq. (1)) and only partial rehydrogenation even under more extreme conditions of $600{ }^{\circ} \mathrm{C}$ and 35 MPa hydrogen. ${ }^{[3,4]}$

$$
\mathrm{LiBH}_{4} \leftrightarrow \mathrm{LiH}+\mathrm{B}+3 / 2 \mathrm{H}_{2}
$$

Developing reactive hydride composites (RHCs) by incorporating metal hydrides has been proven to be an effective strategy for lowering the reaction enthalpy, enhancing the kinetics, and improving the reversible capacity of $\mathrm{LiBH}_{4}$, while preserving the high overall hydrogen density. ${ }^{[5-10]}$ A prototypical RHC is the combination of $\mathrm{LiBH}_{4}$ and $\mathrm{MgH}_{2}$ in a 2:1 molar ratio with a high theoretical hydrogen capacity of 11.4 wt.\% based on Eq. (2), as well as a more advantageous dehydrogenation enthalpy $\left(42 \mathrm{~kJ} \mathrm{~mol}^{-1} \mathrm{H}_{2}\right.$ ) due to the formation of $\mathrm{MgB}_{2 .}{ }^{[5-7]}$

$$
2 \mathrm{LiBH}_{4}+\mathrm{MgH}_{2} \leftrightarrow 2 \mathrm{LiH}+\mathrm{MgB}_{2}+4 \mathrm{H}_{2}
$$

Nevertheless the $2 \mathrm{LiBH}_{4}-\mathrm{MgH}_{2}$ composite still suffers from sluggish kinetics (as a temperature of over $400{ }^{\circ} \mathrm{C}$ is required for an appreciable dehydrogenation rate) and poor reversibility owing to grain growth, phase separation, and particle 
agglomeration during hydrogen sorption cycles at elevated temperature. ${ }^{[6,11,12]}$ Downsizing materials to the nanometer scale has been extensively demonstrated to relieve the inherent limitations to the diffusion of elements in the solid state and facilitate destabilization induced by excess surface energy. ${ }^{[13-15]}$ Due to the high reactivity of both $\mathrm{LiBH}_{4}$ and $\mathrm{MgH}_{2}$, the synthetic strategy of direct synthesis of the $2 \mathrm{LiBH}_{4}-\mathrm{MgH}_{2}$ composite is limited to mechanical milling with uncontrollable size distribution, and, meanwhile, the performance of the mechanically milled composite is degraded during high-temperature cycling, mainly due to the uncontrolled particle growth and/or the aggregation during cycles of hydrogenation and dehydrogenation. ${ }^{[16]}$ An alternative to synthesize and stabilize nanostructured hydrogen storage materials is nanoconfinement via encapsulation in porous scaffolds, leading to the formation of nanosized composite particles under steric confinement, which could effectively preserve the nanostructured morphology during thermal treatment and ensure the cycling stability. ${ }^{[17-19]}$ Nonetheless, the inadequate efficiency, the tedious infiltration process, and a significant degradation of hydrogen capacity due to the massive "dead weight" introduced by inactive scaffolds, which is more obvious for the confinement of a binary composite, are major drawbacks for this strategy. ${ }^{[19-21]}$ In terms of $2 \mathrm{LiBH}_{4}-\mathrm{MgH}_{2}$ composite, the loading capacity reported in the literature is less than $50 \mathrm{wt} \%$ (Table S1 in the Supporting Information). Moreover, in order to achieve the effective nanoconfinement of $2 \mathrm{LiBH}_{4}-\mathrm{MgH}_{2}$ composite, $\mathrm{MgH}_{2}$ and $\mathrm{LiBH}_{4}$ are required to be infiltrated in sequence, due to the lack of suitable 
solvents reported to dissolve both of them or their precursors in the previous literature. ${ }^{[22,23]}$ Hence, the blocking of pores resulting from the preliminary infiltration of $\mathrm{MgH}_{2}$ leads to the inhomogeneous distribution of $\mathrm{LiBH}_{4}$ and prevents direct physical contact between $\mathrm{LiBH}_{4}$ and $\mathrm{MgH}_{2}$, which usually results in their individual decomposition and therefore, inferior dehydrogenation and hydrogenation kinetics and reversibility. ${ }^{[23]}$ As a result, the practical hydrogen storage densities of the whole system for nanoconfined $2 \mathrm{LiBH}_{4}-\mathrm{MgH}_{2}$ composite reported in the literature is further reduced to lower than $4.5 \mathrm{wt} \%$ upon heating to $450{ }^{\circ} \mathrm{C}$ (Table S1). Therefore, the integration of both nanostructure engineering and high capacity to develop an efficient approach to the synthesis of high-performance reactive hydride composites is highly desirable, but remains a great challenge to date.

In this paper, we have adopted a bottom-up self-assembly strategy to controllably synthesize three-dimensional (3D) $\mathrm{MgH}_{2} @$ Graphene (MH@G) porous structure via solvothermal treatment with the assistance of $\mathrm{H}_{2}$ (Figure 1). By taking advantage of MH@G as the "smart nanoreactor", in which flexible and 3D-structured graphene serves as the flexible structure support and $\mathrm{MgH}_{2}$ nanoparticles homogeneously distributed on graphene serve as favorable heterogeneous nucleation sites to uniformly adsorb the solution containing $\mathrm{LiBH}_{4}$ and hence, construct $\mathrm{LiBH}_{4}$ around $\mathrm{MgH}_{2}$ nanoparticles, monodisperse $2 \mathrm{LiBH}_{4}-\mathrm{MgH}_{2}$ nanocomposite $(\mathrm{LBMH} @ \mathrm{G})$ with a particle size of $\sim 10.5 \mathrm{~nm}$ was controllably fabricated on graphene. On the one hand, the nanostructuring of 
$2 \mathrm{LiBH}_{4}-\mathrm{MgH}_{2}$ composite could significantly decrease the phase boundaries between $\mathrm{LiBH}_{4}$ and $\mathrm{MgH}_{2}$, and improve the solid-state diffusion pathways for mass transport during hydrogen storage, alleviating the low mobility of atoms and ions. On the other hand, the resultant 3D architecture can not only provide accessible channels for fast transportation of hydrogen, but is also conductive to preserving the high thermal conductivity of the overall composite for rapid heat transfer during the hydrogen storage cycling, which is induced by the homogeneous distribution of flexible graphene. Moreover, the flexible graphene can prevent the growth and agglomeration of particles, and also can accommodate the stress caused by the large volume changes during consecutive cycles of hydrogen uptake and release, resulting in prolonged cycling lifetime. Altogether, the as-prepared graphene-supported $2 \mathrm{LiBH}_{4}-\mathrm{MgH}_{2}$ nanocomposite with a sandwich-type structure exhibits greatly improved hydrogen storage performance compared to other forms of $2 \mathrm{LiBH}_{4}-\mathrm{MgH}_{2}$, with high energy density, remarkable rate performance, and excellent cycling stability.

\section{Results and discussion:}

The growth of homogeneous $\mathrm{MgH}_{2} \mathrm{NPs}$ anchored in situ on graphene was obtained by a hydrogenation induced solvothermal reaction of dibutyl magnesium at $200{ }^{\circ} \mathrm{C}$ for 24 h. ${ }^{[24]}$ Field-emission scanning electron microscope (FE-SEM) (Figure 2) and transmission electron microscope (TEM) (Figure 3) images clearly show that homogeneous $\mathrm{MgH}_{2}$ NPs with an average particle size of $\sim 5 \mathrm{~nm}$ are immobilized on large single graphene sheets with loading of $20 \%$ for the sample denoted as 
MH20@G. This homogeneous anchoring is attributed to the favorable absorption of dibutyl magnesium and $\mathrm{MgH}_{2}$ on graphene (Figures 2a and 3a). Cross-sectional SEM images show the nanostructures, consisting of alternating layers of $\mathrm{MgH}_{2}$ NPs and graphene stacks in the composite, contains large out-of-plane macropores, afforded by the assembly of graphene sheets, and small mesopores from adding "spacers", i.e., $\mathrm{MgH}_{2} \mathrm{NPs}$, between the graphene sheets (Figure 2b). It is worth noting that the weight fraction of $\mathrm{MgH}_{2} \mathrm{NPs}$ in the as-prepared 3D architectures could be easily controlled by adjusting the concentration of the reactants. With increasing loading from 20\% to 60\% (MH60@G), no aggregation was observed due to the high surface area of graphene as the structural support (Figures $2 \mathrm{~d}$ and 3d). The observation of out-of-plane pores in $M H @ G$ agrees well with the $\mathrm{N}_{2}$ adsorption-desorption analysis (Figure S1a), which exhibits the prominent characteristic of type-IV isotherms with a distinct $\mathrm{H} 2$ hysteresis loop in the $P / P_{o}$ range of $0.4-1.0$, suggesting the presence of relatively large macropores and mesopores in the framework. The mesopore size calculated by the Barrett-Joyner-Halenda (BJH) method is around $3.710 \mathrm{~nm}$ (Figure S1b), and the hybrid features a Brunauer-Emmett-Teller (BET) surface area of up to $794.7 \mathrm{~m}^{2} \mathrm{~g}^{-1}$ and pore volume of $1.368 \mathrm{~cm}^{3} \mathrm{~g}^{-1}$. Combining these results with the SEM observations, it is clear that the porous structure of macropores and mesopores could provide easy pathways for the transportation of $\mathrm{LiBH}_{4}$ solution to facilitate adsorption and nucleation on $\mathrm{MgH}_{2}$ NPs. They also facilitate the transportation of hydrogen during reversible storage, while tolerating the volume changes during 
hydrogen absorption and desorption. High-magnification images reveal that the $\mathrm{MgH}_{2} \mathrm{NPs}$ are isolated from one another within the layer and separated from each other by the graphene stacks, which leaves enough space for the following nucleation of $\mathrm{LiBH}_{4}$ and could effectively circumvent agglomeration. The formation of $\mathrm{MgH}_{2}$ was confirmed based on the X-ray diffraction (XRD) pattern (Figure S2), while high-resolution TEM (HRTEM) images reveal a measured $d$-spacing of $2.25 \AA$, corresponding to the (002) planes of hexagonal $\mathrm{MgH}_{2}$ (inset of Figure 3a), which agrees well with the XRD results.

After infiltration and nucleation of $\mathrm{LiBH}_{4}$, the morphology of $\mathrm{MgH}_{2} @ \mathrm{G}$ is essentially preserved, and the structure of $\mathrm{MgH}_{2}$ remains spherical. Taking advantage of $\mathrm{MgH}_{2} \mathrm{NPs}$ with a relatively high surface energy as heterogeneous sites, which exhibits favorable adsorption of tetrahydrofuran (THF) containing $\mathrm{LiBH}_{4}{ }^{[25]}$, and the hydrophobic nature of graphene, which is incompatible with THF [26, 27], the homogeneous adsorption of the solution around $\mathrm{MgH}_{2} \mathrm{NPs}$ and hence, nucleation of $\mathrm{LiBH}_{4}$ on $\mathrm{MgH}_{2} \mathrm{NPs}$ are favored upon the continous evaporation of THF. A lighter color corresponding to $\mathrm{LiBH}_{4}$ could be clearly observed to uniformly surround the surface of each $\mathrm{MgH}_{2} \mathrm{NP}$ after annealing, as verified by TEM and scanning TEM (STEM) images of LBMH@G (Figure 3b, c, e, f). The presence of $\mathrm{LiBH}_{4}$ alonside $\mathrm{MgH}_{2}$ could be directly validated based on HRTEM image, which verifies the close proximity of a measured d-spacing of $2.25 \AA$, corresponding to the (002) planes of tetragonal $\mathrm{MgH}_{2}$ phase, and $2.53 \AA$, indexed to the (131) planes of tetragonal $\mathrm{LiBH}_{4}$ phase (inset of Figure 3c). The unique architecture of $\mathrm{MH} @ \mathrm{G}$ as the nanoreactor, i.e., 
the porous structure, which could promote the transfer and uniform distribution of $\mathrm{LiBH}_{4}$ on each $\mathrm{MgH}_{2}$ NP (Figure 2b, f), the flexible graphene, which could effectively prevent the growth of $\mathrm{LiBH}_{4}$ during the nucleation process, and the homogenous distribution of $\mathrm{MgH}_{2} \mathrm{NPs}$ on graphene, leads to the uniform distribution of the resulting $\mathrm{LiBH}_{4}-\mathrm{MgH}_{2}$ nanocomposite (Figure 2e and Figure 3e, f), even with a loading of $80 \%$. Therefore an average particle size of $\sim 10.5 \mathrm{~nm}$ with good size distribution was observed for the as-prepared $\mathrm{LiBH}_{4}-\mathrm{MgH}_{2}$ nanocomposite in LBMH80@G. Energy dispersive X-ray spectroscopy (EDS) results for the thermally annealed LBMH80@G hybrid shown in Figure S3 demonstrate the presence of B (corresponding to $\mathrm{LiBH}_{4}$ ), $\mathrm{Mg}$ (corresponding to $\mathrm{MgH}_{2}$ ), and $\mathrm{C}$ (corresponding to graphene) in the composite. The corresponding elemental mapping analysis obviously shows the well-defined spatial distribution of all the elements, validating the good distribution of $2 \mathrm{LiBH}_{4}-\mathrm{MgH}_{2}$ nanocomposite in the composites (Figure $3 \mathrm{~g}$ ). The presence of $\mathrm{LiBH}_{4}$ and $\mathrm{MgH}_{2}$ in $\mathrm{LBMH} 80 @ \mathrm{G}$ could be directly supported by the X-ray diffraction (XRD) results (Figure S4), in which all the prominent peaks match well with the phase of $\mathrm{LiBH}_{4}$ and $\mathrm{MgH}_{2}$, which is consistent with the HRTEM results.

The hydrogen storage performance of the graphene-supported $2 \mathrm{LiBH}_{4}-\mathrm{MgH}_{2}$ nanocomposites was firstly examined by simultaneous thermogravimetric analysis coupled with mass spectroscopy (TGA-MS). As illustrated in Figure 4a and b, the bulk $2 \mathrm{LiBH}_{4}-\mathrm{MgH}_{2}$ composite starts to release hydrogen at $\sim 354{ }^{\circ} \mathrm{C}$, with two main desorption peaks at $\sim 364{ }^{\circ} \mathrm{C}$ and $431{ }^{\circ} \mathrm{C}$, corresponding to the decomposition of $\mathrm{MgH}_{2}$ and $\mathrm{LiBH}_{4}$, respectively, and a total mass loss of $7.5 \mathrm{wt} . \%$ was observed 
when the sample was heated to $450{ }^{\circ} \mathrm{C}$. By comparison, the onset temperature of all the graphene-supported $2 \mathrm{LiBH}_{4}-\mathrm{MgH}_{2}$ nanocomposites is downshifted to $\sim 235$ ${ }^{\circ} \mathrm{C}$, followed by a shoulder before the peak temperature, which is mainly attributed to the decomposition of $\mathrm{MgH}_{2}$ and $\mathrm{LiBH}_{4}$, respectively. Specifically, a weight loss of $\sim 4.4$ wt.\% could be achieved for LBMH40@G, which is close to the theoretical value (4.56 wt.\%), indicating complete dehydrogenation within the temperature range from room temperature to only $365{ }^{\circ} \mathrm{C}$. With increased loading of the $2 \mathrm{LiBH}_{4}-\mathrm{MgH}_{2}$ nanocomposites from $40 \%$ to $80 \%$, the released $\mathrm{H}_{2}$ capacity increases correspondingly, with only a slight increase in the peak temperature from $328{ }^{\circ} \mathrm{C}$ to $345^{\circ} \mathrm{C}$, which is attributed to the homogeneous distribution. Specifically, a $\mathrm{H}_{2}$ capacity of 9.1 wt.\% was obtained for LBMH80@G, and its dehydrogenation could be completed before $375{ }^{\circ} \mathrm{C}$, much lower than even the onset temperature of the $2^{\text {nd }}$ step decomposition from the bulk $2 \mathrm{LiBH}_{4}-\mathrm{MgH}_{2}$ composite. Furthermore, no measureable release of $\mathrm{B}_{2} \mathrm{H}_{6}$, which was detected upon the simultaneous decomposition of bulk $2 \mathrm{LiBH}_{4}-\mathrm{MgH}_{2}$ composite and is a harmful impurity for the applications of hydrogen storage materials, was observed during the dehydrogenation of LBMH80@G (Figure S5). The storage capacity is further confirmed by the volumetric results, which also authenticates the high-purity of released hydrogen (Figure S6). This indicates that well-organized nanostructures of $2 \mathrm{LiBH}_{4}-\mathrm{MgH}_{2}$ composite are distributed on the graphene, as verified by microscopic images, which endows the composite with significantly enhanced hydrogen storage performance. 
It has been clarified that, at elevated temperature and low hydrogen pressure, individual decomposition of $\mathrm{LiBH}_{4}$ is both thermodynamically allowed and kinetically favored, which could hinder the reaction between $\mathrm{LiBH}_{4}$ and $\mathrm{MgH}_{2}$ to form $\mathrm{MgB}_{2}$ and hence, impede the favorable reversiblity of the $\mathrm{LiBH}_{4}-\mathrm{MgH}_{2}$ system based on Eq. (2). ${ }^{[5,28-30]}$ Experimental results have confirmed that a hydrogen back pressure of at least $0.3 \mathrm{MPa}$ during dehydrogenation is required to suppress the individual decomposition of $\mathrm{LiBH}_{4}$ and favor the reversible reaction between $\mathrm{Mg}$ and $\mathrm{LiBH}_{4}$ to produce $\mathrm{LiH}$ and $\mathrm{MgB}_{2} \cdot{ }^{[11]}$ Therefore, in order to further confirm the effects of the well-organized architecture towards promoting the kinetics and cycling performance of $2 \mathrm{LiBH}_{4}-\mathrm{MgH}_{2}$ nanocomposite, isothermal volumetric desorption measurements at various temperatures (Figure $4 \mathrm{c}$ and $\mathrm{d}$ ) were conducted with an initial hydrogen back pressure of $0.3 \mathrm{MPa}$. An incubation period of more than $10 \mathrm{~h}$ for the second dehydrogenation step is observed for the ball-milled $2 \mathrm{LiBH}_{4}-\mathrm{MgH}_{2}$ composite with the sizes of most of the particles larger than $500 \mathrm{~nm}$ (Figure S7), even at a temperature of $400{ }^{\circ} \mathrm{C}$, due to the sluggish nucleation of $\mathrm{MgB}_{2}$, which significantly degrades the desorption kinetics and is a major issue for the application of this material. On the contrary, no incubation period was observed for any of the graphene-supported $2 \mathrm{LiBH}_{4}-\mathrm{MgH}_{2}$ nanocomposites, and only less than $20 \mathrm{~min}$ is required to complete the dehydrogenation for LBMH40@G. Although the dehydrogenation rate slightly decreased with increasing loading capacity to $80 \%$, LBMH80@G is still capable of approaching saturation of the hydrogen release process at $400{ }^{\circ} \mathrm{C}$ over the period 
of only $40 \mathrm{~min}$, so that it exhibits a hydrogen capacity of $9.1 \mathrm{wt} \%$ in overall composite mass, much higher than even the practical capacity of its bulk counterpart. Moreover, a complete dehydrogenation (9.0 wt.\%) could also be achieved by decreasing the operating temperature down to $325^{\circ} \mathrm{C}$ with a holding time of $180 \mathrm{~min}$, as verified by the disappearance of $\mathrm{LiBH}_{4}$ and $\mathrm{MgH}_{2}$, and the formation of $\mathrm{MgB}_{2}$ and $\mathrm{LiH}$ in the powder XRD results (Figure S8), while only a capacity of 2.9 wt.\%, corresponding to the decomposition of $\mathrm{MgH}_{2}$, was observed in the bulk $2 \mathrm{LiBH}_{4}-\mathrm{MgH}_{2}$ composite, even when heated at $400{ }^{\circ} \mathrm{C}$ within the same period. This confirms a significant improvement in the dehydriding kinetics in the nanocomposites in comparison with their bulk counterpart due to the decrease in the particle size down to nanometer range and the close proximity between the $\mathrm{MgH}_{2}$ and the $\mathrm{LiBH}_{4}$, which facilitates the solid-state reaction between $\mathrm{Mg}$ and $\mathrm{LiBH}_{4}$ towards the formation of $\mathrm{MgB}_{2}$, owing to the much shortened length scales of the phase separation and mass transport.

The thermodynamics of graphene-supported $2 \mathrm{LiBH}_{4}-\mathrm{MgH}_{2}$ nanocomposite is further determined from a series of pressure-composition-temperature (PCT) curves derived from the van't Hoff plot based on the $\mathrm{H}_{2}$ absorption and desorption isotherms (Figure S9). The enthalpy $(\Delta \mathrm{H})$ of hydrogenation of graphene-supported $2 \mathrm{LiBH}_{4}-\mathrm{MgH}_{2}$ nanocomposite is calculated to be $\sim 39.2 \mathrm{~kJ} \mathrm{~mol}^{-1} \mathrm{H}_{2}$ according to the slope of van't Hoff plot, which is comparable to the value reported for the bulk counterpart (40.2 $\mathrm{kJ} \mathrm{mol}^{-1} \mathrm{H}_{2}$ ), attributed to the hydrogenation of $\mathrm{MgB}_{2}$ and $\mathrm{LiH}$ to form $2 \mathrm{LiBH}_{4}-\mathrm{MgH}_{2}$ nanocomposite. ${ }^{[5]}$ By comparison, since the dehydrogenation 
process of bulk $2 \mathrm{LiBH}_{4}-\mathrm{MgH}_{2}$ composite in general involves the individual decomposition of $\mathrm{LiBH}_{4}$ and $\mathrm{Mg}$ due to the sluggish interaction between $\mathrm{Mg}$ and $\mathrm{LiBH}_{4}$ and/or the interaction of $\mathrm{Mg}$ with $\mathrm{B}$ to form $\mathrm{MgB}_{2}$ (Figures $\mathrm{S} 10-12$ ), the enthalpy changes of bulk $2 \mathrm{LiBH}_{4}-\mathrm{MgH}_{2}$ composite for dehydrogenation (69.2-71 kJ $\mathrm{mol}^{-1} \mathrm{H}_{2}$ ) is much larger than for the hydrogenation in the previous literature. ${ }^{[31,32]}$ Interestingly, the enthalpy changes of dehydrogenation of $2 \mathrm{LiBH}_{4}-\mathrm{MgH}_{2}$ nanocomposite are calculated to be $\sim 46.8 \mathrm{~kJ} \mathrm{~mol}^{-1} \mathrm{H}_{2}$, which is significantly lower than the relative value of the bulk counterpart attributed to the favorable formation of $\mathrm{MgB}_{2}$ and $\mathrm{LiH}$ from $\mathrm{Mg}$ and $\mathrm{LiBH}_{4}$ towards hydrogen release as verified by $\mathrm{XRD}$, FTIR and solid-state ${ }^{11} \mathrm{~B}$ NMR results (Figures S10-12). It is concluded that the significantly enhanced dehydrogenation kinetics and close proximity between $\mathrm{MgH}_{2}$ and $\mathrm{LiBH}_{4}$ induced by the significant decrease of particle size (Figure 4) leads to the complete and favorable interaction between $\mathrm{Mg}$ and $\mathrm{LiBH}_{4}$ to form $\mathrm{MgB}_{2}$ in the equilibration time and a tremendously decreased hysteresis between absorption and desorption equilibrium pressures in comparison with bulk counterpart.

The long-term kinetic measurements, an important challenging and key aspect in practical hydrogen storage applications, were carried out by isothermal hydrogenation and dehydrogenation at $350{ }^{\circ} \mathrm{C}$, using the volumetric method to evaluate the cycling performance of graphene-supported $2 \mathrm{LiBH}_{4}-\mathrm{MgH}_{2}$ nanocomposite compared with its bulk counterpart (Figure 5a). It was revealed that the capacity of the bulk $2 \mathrm{LiBH}_{4}-\mathrm{MgH}_{2}$ composite was only $\sim 2.8 \mathrm{wt} \%$ with a dwell time of $200 \mathrm{~min}$ for the first cycle, and $~ 2.88 \mathrm{wt} \%$ of hydrogen was desorbed, 
even after consecutive thermal activation during three cycles of hydrogen storage. By contrast, the graphene-supported 2 $\mathrm{LiBH}_{4}-\mathrm{MgH}_{2}$ nanocomposite (LBMH80@G) delivers a capacity of $\sim 9.1 \mathrm{wt} . \%$ in the $1^{\text {st }}$ cycle, which far exceeds the values reported in the previous literature (Table S1), as well the US Department of Energy (DOE) 2020 targets for onboard hydrogen storage systems (i.e., 5.5 wt.\%). No degradation is observed, and there is capacity retention of $\sim 98 \%$, even through 25 full cycles (Figure 5b). Furthermore, the kinetics of dehydrogenation from graphene-supported $2 \mathrm{LiBH}_{4}-\mathrm{MgH}_{2}$ nanocomposite is well-preserved from the first to the last cycle, and a complete hydrogen release process could be realized within less than $100 \mathrm{~min}$, in which the nanocomposite exhibits a capacity of 8.92 wt.\% hydrogen during the $25^{\text {th }}$ cycle. No impurity was detected by mass spectra during the $15^{\text {th }}$ and $25^{\text {th }}$ cycle of dehydrogenation (Figure S5) and charicteristic peaks indexed to $\mathrm{LiBH}_{4}$ and $\mathrm{MgH}_{2}$ with absence of any byproducts could be found in the products after $10^{\text {th }}$ and $15^{\text {th }}$ cycle of hydrogenation (Figure S13), which endorses the well cycling stablity of graphene-supported $2 \mathrm{LiBH}_{4}-\mathrm{MgH}_{2}$ nanocomposite. The morphology changes in the graphene-supported $2 \mathrm{LiBH}_{4}-\mathrm{MgH}_{2}$ nanocomposite were investigated at the end of the $15^{\text {th }}$ dehydrogenation (Figure $5 \mathrm{c}-\mathrm{e}$ ), which showed that the nanostructure at this stage is well maintained and very similar to that observed in the freshly prepared sample, without any appearance of physical damage and obvious aggregation. The uniform dispersion of dehydrogenated products could be clearly observed in STEM image (Figure 5d) although with a wider size distribution and a larger mean particle size $(\sim 16 \mathrm{~nm})$ through 15 cycles 
of hydrogenation and dehydrogenation in comparison with the freshly-prepared nanocomposite. The morphology changes in the graphene-supported $2 \mathrm{LiBH}_{4}-\mathrm{MgH}_{2}$ nanocomposite were investigated at the end of the $15^{\text {th }}$ dehydrogenation, which showed that the nanostructure at this stage is well maintained and very similar to that observed in the freshly prepared sample, without any appearance of physical damage. After 15 cycles of dehydrogenation for LBMH80@G, the formation of $\mathrm{MgB}_{2}$ could be directly confirmed in a HRTEM image (inset of Figure 5e) by the presence of interplanar spacing of $0.21 \mathrm{~nm}$, which can be assigned to the (101) planes of hexagonal $\mathrm{MgB}_{2}$. The corresponding elemental mapping (Figure 5f) further validates the uniform distribution of $\mathrm{LiBH}_{4}$ and $\mathrm{MgH}_{2}$ in the dehydrogenated products after 15 cycles. It demonstrates that exceptional cycling capability could be attributed to the highly uniform $2 \mathrm{LiBH}_{4}-\mathrm{MgH}_{2}$ nanocomposite distributed on graphene and the stable architecture of the hydrogen storage materials.

In the light of these observations, the superior hydrogen storage performance and cycling stability of graphene-supported $2 \mathrm{LiBH}_{4}-\mathrm{MgH}_{2}$ nanocomposite can be mainly ascribed to several unique features. First, the high surface area of graphene and the unique self-assembly strategy make it possible to realize the high loading of uniform $\mathrm{MgH}_{2}$ NPs and hence $\mathrm{LiBH}_{4} \mathrm{NPs}$, which ensures the high capacity of the system (Figure 1). Secondly, the significant reduction of particle size down to the nanometer scale can not only develop close contact between $\mathrm{LiBH}_{4}$ and $\mathrm{MgH}_{2}$, but also significantly decreases the diffusion distances for the solid-state reaction 
between $\mathrm{LiBH}_{4}$ and $\mathrm{MgH}_{2}$, and enhances surface interactions (Figures 2 and 3), leading to tremendously improved hydrogen storage kinetics (Figure 4) and favorable formation of $\mathrm{MgB}_{2}$ from the interaction between $\mathrm{Mg}$ and $\mathrm{LiBH}_{4}$ during dehydrogenation. Moreover, the obtained $2 \mathrm{LiBH}_{4}-\mathrm{MgH}_{2}$ nanocomposite is homogeneously anchored into the porous skeleton of graphene with close and robust physical contact, which could ensure fast heat transfer induced by the high thermal conductivity of graphene and, simultaneously, effectively avoid the aggregation of the as-synthesized nanoparticles from the opposite side of graphene sheets during the hydrogen storage process (Figure 5). In addition, the particle size of $2 \mathrm{LiBH}_{4}-\mathrm{MgH}_{2}$ nanocomposite down to only $\sim 10.5 \mathrm{~nm}$ and the relatively clear interparticle space between the as-synthesized nanocomposite coupled with the steric confinement and structural support effects of porous graphene could effectively alleviate particle growth and sintering effects, resulting in a well-preserved morphological nanostructure and excellent cycling stability (Figure 5). Therefore, the well-designed graphene-supported $2 \mathrm{LiBH}_{4}-\mathrm{MgH}_{2}$ nanocomposite exhibits exceptionally high hydrogen storage capacity, significantly improved dehydrogenation kinetics, and excellent cycling stability.

\section{Conclusions}

In summary, we have demonstrated the rational fabrication of a nanostructured binary composite, i.e., $2 \mathrm{LiBH}_{4}-\mathrm{MgH}_{2}$, with homogeneous particle size of $\sim 10.5 \mathrm{~nm}$, uniform distribution on graphene, and high loading capacity, by using flexible graphene as the structural support and homogeneous $\mathrm{MgH}_{2}$ NPs directly self-assembled on graphene 
as the heterogeneous nucleation sites. The sandwich-structure formed in-situ during the self-assembly of $\mathrm{MgH}_{2}$ on graphene with large pore volumes and specific surface areas can facilitate the penetration of $\mathrm{LiBH}_{4}$ and maximize the amount of loading of $2 \mathrm{LiBH}_{4}-\mathrm{MgH}_{2}$ nanocomposite, in addition to maintaining mechanical integrity towards stable cycling stability. Meanwhile, graphene can enhance the thermal transport during the charging and discharging of hydrogen. Due to the synergetic effects induced by this unique structure, graphene-supported $2 \mathrm{LiBH}_{4}-\mathrm{MgH}_{2}$ nanocomposite exhibits a significantly decreased dehydrogenation temperature, high reversible $\mathrm{H}_{2}$ capacity (9.1 wt.\% in the overall composite), and good cycling stability (a reversible capacity of $8.9 \mathrm{wt} . \%$ after 25 complete cycles at $350{ }^{\circ} \mathrm{C}$ ). This work not only offers a new approach to developing high-performance binary hydrogen storage materials, but also opens the way towards fabrication of graphene-supported multiphase composites for a large spectrum of applications.

\section{Experimental details}

Preparation of graphene-supported $\mathrm{MgH}_{2}$ nanoparticles: Graphene-supported $\mathrm{MgH}_{2} \mathrm{NPs}$ were fabricated through the hydrogenation of di- $n$-butylmagnesium $\left(\mathrm{MgBu}_{2}\right)$ in cyclohexane. ${ }^{[24]}$ In a typical synthesis of $\mathrm{MH} 20 @ \mathrm{G}, 0.0132 \mathrm{~g}$ graphene was first mixed with $1.6 \mathrm{~mL} \mathrm{MgBu}_{2}$ solution and $40 \mathrm{~mL}$ cyclohexane in a pressure reactor vessel to achieve a homogeneous dispersion. The solution was then heated up to $200{ }^{\circ} \mathrm{C}$ with vigorous stirring under a hydrogen pressure of $35 \mathrm{~atm}$. After reaction for $24 \mathrm{~h}$, the product was collected by centrifugation and further dried using dynamic vacuum on a Schlenk line, to form graphene-supported $\mathrm{MgH}_{2} \mathrm{NPs}$. 
By changing the ratio between $\mathrm{MgBu}_{2}$ and graphene, loading ratios of $40 \mathrm{wt} . \%$ and 60 wt. $\%$ could be fabricated.

Preparation of graphene-supported $2 \mathrm{LiBH}_{4}-\mathrm{MgH}_{2}$ nanocomposite: The synthesis of $2 \mathrm{LiBH}_{4}-\mathrm{MgH}_{2}$ nanocomposite is achieved by adopting the thus-formed graphene-supported $\mathrm{MgH}_{2} \mathrm{NPs}$ as the nanoreactors, which were immersed in a solution of $\mathrm{LiBH}_{4}$ in THF. After sonication and stirring for $30 \mathrm{~min}$, the product was vacuum-dried at room temperature and then slowly heated up to $150{ }^{\circ} \mathrm{C}$ to remove the solvent. The molar ratio of $\mathrm{LiBH}_{4}$ to $\mathrm{MgH}_{2}$ was 2.05:1.

Preparation of bulk $2 \mathrm{LiBH}_{4}-\mathrm{MgH}_{2}$ composite: the ball-milling of $\mathrm{LiBH}_{4}$ and $\mathrm{MgH}_{2}$ with a molar ratio of 2:1 was carried out using a planetary QM-1SP2 for $4 \mathrm{~h}$. The ball-to-powder ratio was 40:1, with a milling speed of $400 \mathrm{rpm}$. The milling procedure was conducted by alternating between $30 \mathrm{~min}$ of milling and $10 \mathrm{~min}$ of rest. All manipulation of materials was performed in an argon-filled glove box with $\mathrm{H}_{2} \mathrm{O}$ and $\mathrm{O}_{2}$ levels below 1 ppm to prevent contamination by air.

Materials characterization: Thermogravimetric analysis (TGA; Netzsch STA 449 F3) in conjunction with mass spectrometry (MS; Hidden HPR 20) was carried out under dynamic argon with a heating rate of $5{ }^{\circ} \mathrm{C} \min ^{-1}$ and a purge rate of 80 $\mathrm{ml} \min ^{-1}$. X-ray diffraction (XRD) patterns were collected on a D8 Advance, Bruker AXS with $\mathrm{Cu} \mathrm{K} \alpha$ radiation. Amorphous tape was used to cover samples during the XRD measurements to avoid any possible reactions between the sample and air. Nitrogen absorption/desorption isotherms were collected on a Quantachrome NOVA 4200e instrument at the temperature of liquid nitrogen. The 
pore volumes and pore size distributions were obtained from the adsorption branches of isotherms, in accordance with the Barrett-Joyner-Halenda (BJH) model. Field-emission scanning electron microscope (FE-SEM) images were obtained using a JEOL 7500FA microscope. Transmission electron microscope (TEM) images were collected on a JEOL $2011 \mathrm{~F}$. Solid-state ${ }^{11} \mathrm{~B}$ magic angle spinning nuclear magnetic resonance (MAS NMR) were conducted on a Bruker AVANCE $500 \mathrm{MHz}$ spectrometer at room temperature. The chemical shifts for the

${ }^{11} \mathrm{~B}$ nuclei are referenced to $\mathrm{LiBH}_{4}$ at $-41 \mathrm{ppm}$.

The hydrogen storage performance of the as-prepared samples were studied on a Sieverts apparatus (GRC, Advanced Materials Corp., USA). The desorption properties were determined at various temperatures under a hydrogen pressure of 0.3 MPa. For cycling tests, the as-prepared composites were firstly hydrogenated at $350{ }^{\circ} \mathrm{C}$ under a initial $\mathrm{H}_{2}$ pressure of $8 \mathrm{MPa}$, and then the dehydrogenation was conducted at the same temperature under a hydrogen pressure of $0.3 \mathrm{MPa}$. Pressure-composition-temperature (PCT) measurements were conducted at the desired temperatures, and the equilibrium time for each point was set to $600 \mathrm{~s}$.

\section{Acknowledgements}

This work was partially supported by the National Natural Science Foundation of China (21271046, 51471053), the PhD Programs Foundation of the Ministry of Education of China (20110071110009). Z. Guo acknowledges the financial support provided by the Australian Research Council (ARC) through an ARC Discovery Project (DP140102858). The authors also would like to thank Dr. Tania Silver for 
critical reading of the manuscript.

Supporting Information Available: Supplementary data associated with this article can be found in the online version at $\mathrm{xxx}$. 


\section{References}

[1] L. Schlapbach, A. Züttel, Nature 414 (2001), 353.

[2] S.-i. Orimo, Y. Nakamori, J. R. Eliseo, A. Züttel, C. M. Jensen, Chem. Rev. 107 (2007), 4111.

[3] A. Züttel, P. Wenger, S. Rentsch, P. Sudan, P. Mauron, C. Emmenegger, J. Power Sources 118 (2003), 1.

[4] A. Züttel, S. Rentsch, P. Fischer, P. Wenger, P. Sudan, P. Mauron, C. Emmenegger, J. Alloys Compd. 356-357 (2003), 515.

[5] J. J. Vajo, S. L. Skeith, F. Mertens, J. Phys. Chem. B 109 (2005), 3719.

[6] U. Bösenberg, S. Doppiu, L. Mosegaard, G. Barkhordarian, N. Eigen, A. Borgschulte, T. R. Jensen, Y. Cerenius, O. Gutfleisch, T. Klassen, M. Dornheim, R. Bormann, Acta Mater. 55 (2007), 3951.

[7] J. J. Vajo, G. L. Olson, Scripta Mater. 56 (2007), 829.

[8] J. Yang, A. Sudik, C. Wolverton, J. Phys. Chem. C 111 (2007), 19134.

[9] S. A. Jin, Y. S. Lee, J. H. Shim, Y. W. Cho, J. Phys. Chem. C 112 (2008), 9520.

[10] X. Xiao, L. Zhang, X. Fan, L. Han, J. Shao, S. Li, H. Ge, Q. Wang, L. X. Chen, J. Phys. Chem. C 117 (2013), 12019.

[11] F. E. Pinkerton, M. S. Meyer, G. P. Meisner, M. P. Balogh, J. J. Vajo, J. Phys. Chem. C 111 (2007), 12881.

[12] K. B. Kim, J. H. Shim, S. H. Park, I. S. Choi, K. H. Oh, Y. W. Cho, J. Phys. Chem. C 119 (2015), 9714.

[13] T. K. Nielsen, F. Besenbacher, T. R. Jensen, Nanoscale 3 (2011), 2086.

[14] M. Fichtner, Phys. Chem. Chem. Phys. 13 (2011), 21186. 
[15] P. E. de Jongh, P. Adelhelm, ChemSusChem 3 (2010), 1332.

[16] B. H. Liu, B. J. Zhang, Y. Jiang, Int. J. Hydrogen Energy 36 (2011), 5418.

[17] P. E. de Jongh, M. Allendorf, J. J. Vajo, C. Zlotea, MRS Bull. 38 (2013), 488.

[18] F. Schüth, Chem. Mater. 26 (2013), 423.

[19] J. Shao, X. Xiao, X. Fan, X. Huang, B. Zhai, S. Li, H. Ge, Q. Wang, Nano Energy 15 (2015), 244.

[20] M. L. Christian, K. F. Aguey-Zinsou, ACS Nano 6 (2012), 7739.

[21] G. L. Xia, D. Li, X. Chen, Y. Tan, Z. Tang, Z. Guo, H. Liu, Z. Liu, X. B. Yu, Adv. Mater. 25 (2013), 6238

[22] T. K. Nielsen, U. Bösenberg, R. Gosalawit, M. Dornheim, Y. Cerenius, F. Besenbacher, T. R. Jensen, ACS Nano 4 (2010), 3903.

[23] K. Wang, X. Kang, Y. Zhong, C. Hu, J. Ren, P. Wang, J. Phys. Chem. C 118 (2014), 26447.

[24] G. L. Xia, Y. Tan, X. Chen, D. L. Sun, Z. P. Guo, H. K. Liu, L. Z. Ouyang, M. Zhu, X. B. Yu, Adv. Mater. 27 (2015), 5981

[25] X. Z. Xiao, Z. Liu, S. Saremi-Yarahmadi, D. H. Gregory, Phys. Chem. Chem. Phys. 18 (2016) 10492.

[26] S. Park, J. An, I. Jung, R. D. Piner, S. J. An, X. Li, A. Velamakanni, R. S. Ruoff, Nano Lett. 9 (2009), 1593

[27] S. Stankovich, D. A. Dikin, R. D. Piner, K. A. Kohlhaas, A. Kleinhammes, Y. Jia, Y. Wu, S. T. Nguyen, R. S. Ruoff, Carbon 45 (2007), 1558.

[28] U. Bösenberg, D. B. Ravnsbæk, H. Hagemann, V. D’Anna, C. B. Minella, C. Pistidda, W. van Beek, T. R. Jensen, R. Bormann, M. Dornheim, J. Phys. Chem. C 114 (2010), 15212. 
[29] P. Chen, T. Y. Xiao, H. H. Li, J. Yang, Z. Wang, H. Yao, S. H. Yu, ACS Nano 6 (2011), 712.

[30] U. Bösenberg, J. W. Kim, D. Gosslar, N. Eigen, T. R. Jensen, J. M. B. von Colbe, Y. Zhou, M.

Dahms, D. H. Kim, R. Günther, Y. W. Cho, K. H. Oh, T. Klassen, R. Bormann, M. Dornheim, Acta Mater. 58 (2010), 3381.

[31] H. Y. Shao, M. Felderhoff, C. Weidenthaler, J. Phys. Chem. C 119 (2015), 2341.

[32] S. T. Sabitu, A. J. Goudy, J. Phys. Chem. C 116 (2012), 13545. 


\section{Figure captions:}

Figure 1. Schematic illustration of the fabrication of graphene-supported 2 $\mathrm{LiBH}_{4}-\mathrm{MgH}_{2}$ nanocomposite: (1) self-assembly of uniform $\mathrm{MgH}_{2} \mathrm{NPs}$ on graphene via solvothermal treatment; (2) infiltration of $\mathrm{LiBH}_{4}$ solution; $(3,4)$ removal of solvent and heterogeneous nucleation of $\mathrm{LiBH}_{4}$ on $\mathrm{MgH}_{2} \mathrm{NPs}$.

Figure 2. SEM images of (a) MH20@G, (c) LBMH40@G, (d) MH60@G, and (e) LBMH80@G; and cross-sectional SEM images of (b) MH20@G and (f) LBMH80@G.

Figure 3. TEM images of (a) MH20@G, (b) LBMH40@G, (d) MH60@G and (e) LBMH80@G. STEM images of (c) LBMH40@G, with inset containing a HRTEM image, and (f) LBMH80@G. (g) Elemental mapping of LBMH80@G. The insets in (a) are a HRTEM image (top right) and a FFT spectrum of $\mathrm{MgH}_{2} \mathrm{NPs}$ (bottom left).

Figure 4. Thermogravimetric analysis curves (a) and mass spectra (b) of the as-prepared $2 \mathrm{LiBH}_{4}-\mathrm{MgH}_{2}$ nanocomposites anchored on graphene with various loadings compared with the ball-milled composite (bulk). (c) Isothermal dehydrogenation of graphene-supported $2 \mathrm{LiBH}_{4}-\mathrm{MgH}_{2}$ nanocomposites with various loadings in comparison with their ball-milled counterpart at $400{ }^{\circ} \mathrm{C}$ under $0.3 \mathrm{MPa}$ hydrogen back pressure, where the $\mathrm{H}_{2}$ contents are expressed per mass of $2 \mathrm{LiBH}_{4}-\mathrm{MgH}_{2}$ nanocomposite (with the $\mathrm{H}_{2}$ content expressed per mass of whole composite shown in the inset); and (d) isothermal dehydrogenation of LBMH80@G at various temperatures under a back pressure of $0.3 \mathrm{MPa}$.

Figure 5. (a) Long-term cycling performance of the dehydrogenation (under a back pressure of $0.3 \mathrm{MPa}$ ) and hydrogenation for $\mathrm{LBMH} 80 @ \mathrm{G}$ and bulk $2 \mathrm{LiBH}_{4}-\mathrm{MgH}_{2}$ composite at $350{ }^{\circ} \mathrm{C}$; (b) normalized $\mathrm{H}_{2}$ capacity as a function of cycle number, where the hydrogen capacities are normalized to the theoretical value of $2 \mathrm{LiBH}_{4}-\mathrm{MgH}_{2}$ composite; SEM (c), STEM (d), and TEM (e) images, with the inset containing a HRTEM image LBMH80@G after 15 cycles of dehydrogenation; and (f) elemental mapping of LBMH80@G after 15 cycles of hydrogenation. The $\mathrm{H}_{2}$ capacity is expressed here per mass of the whole composite. 
Figure 1

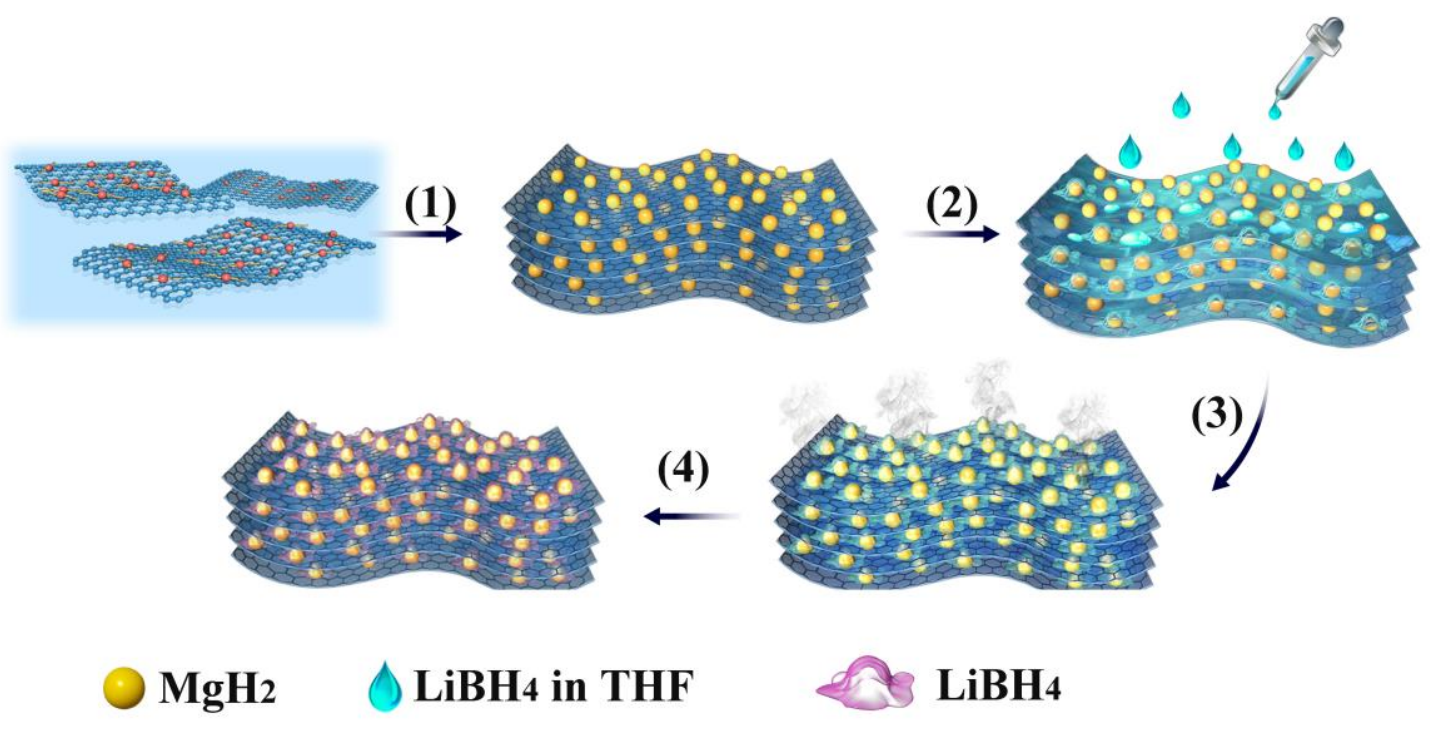


Figure 2
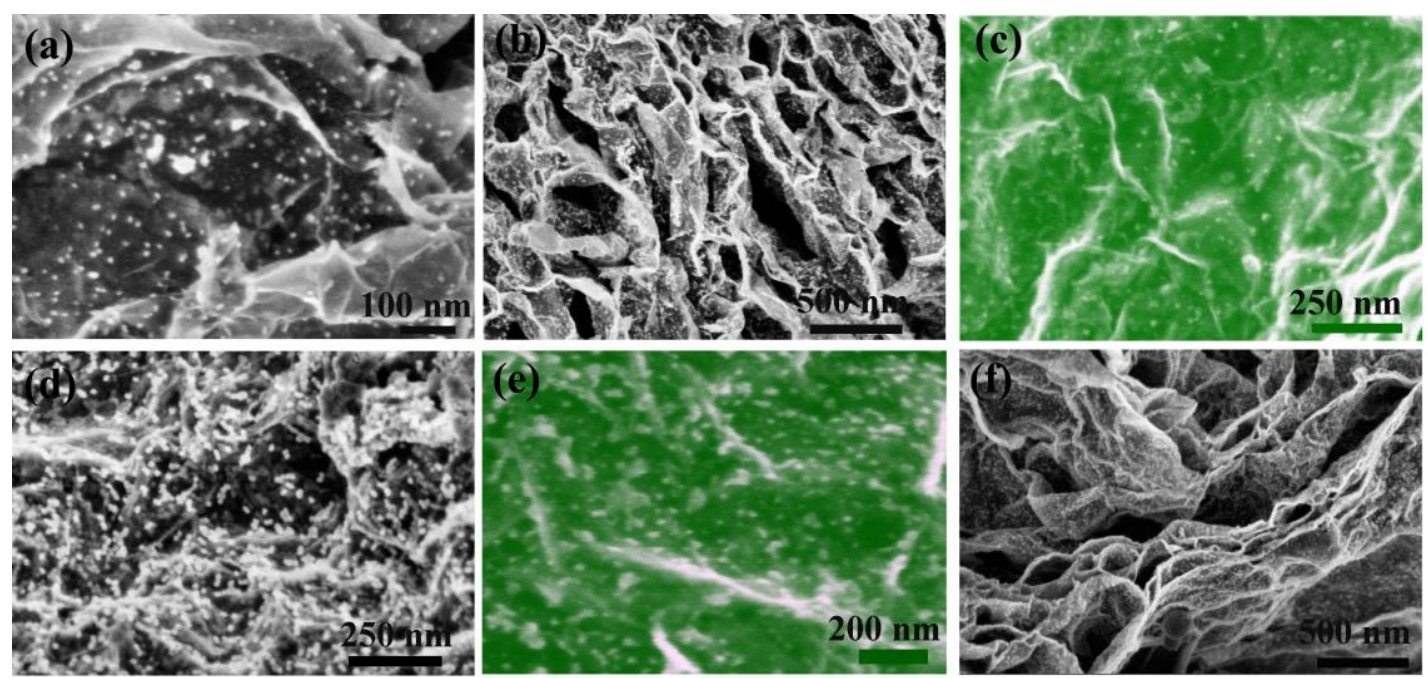
Figure 3
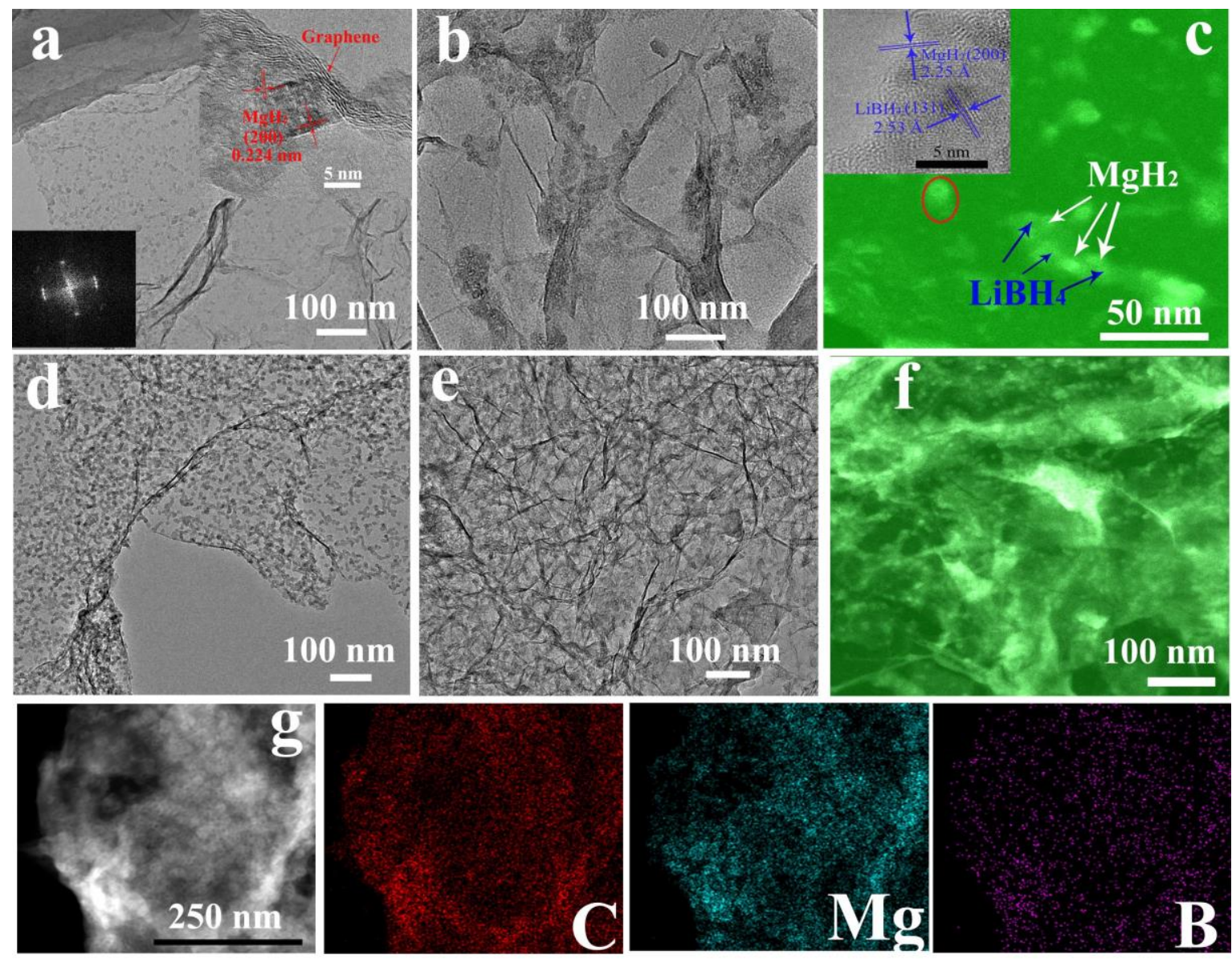
Figure 4
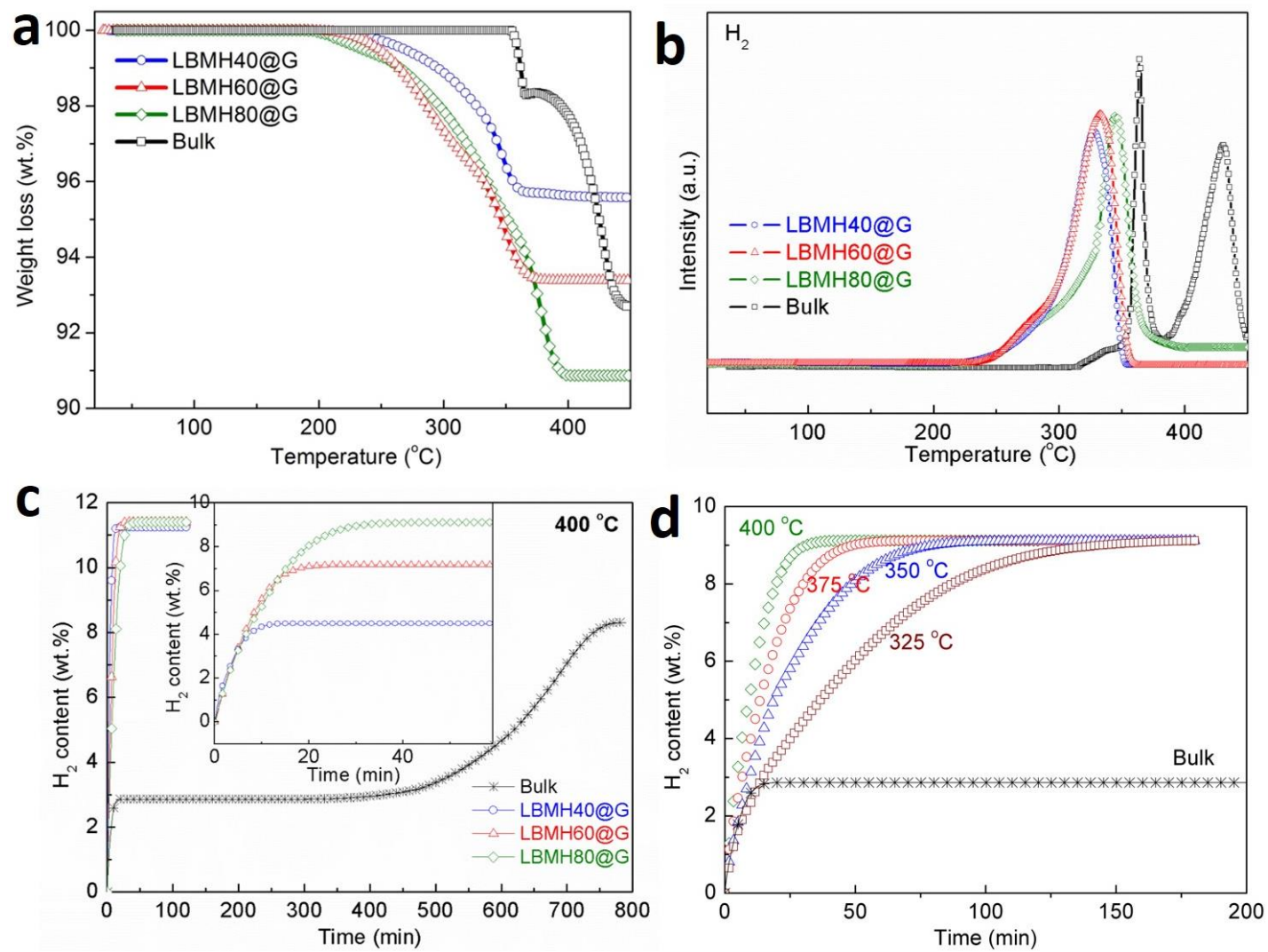
Figure 5
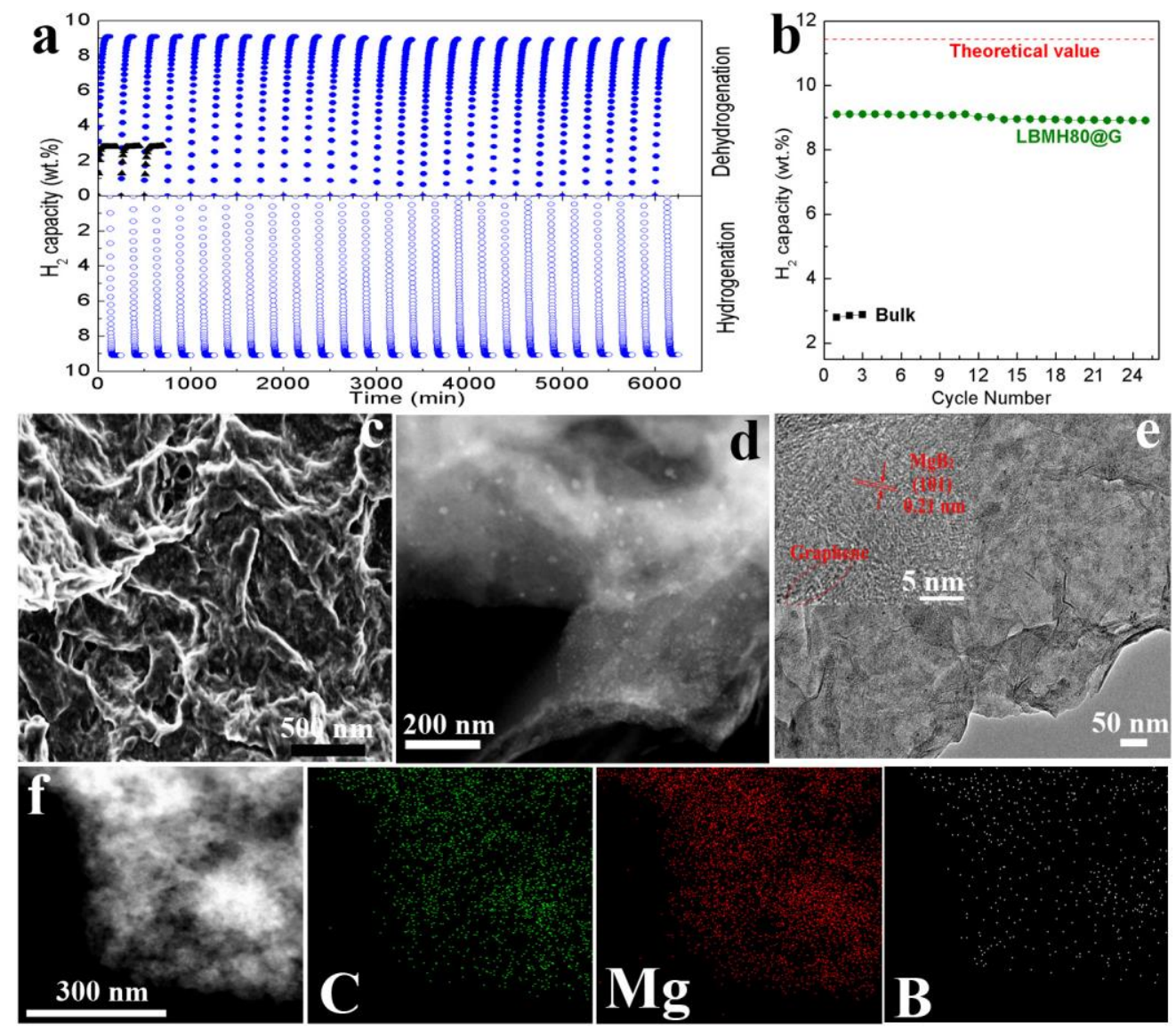